\title{
Protective/restorative role of the adipose tissue-derived mesenchymal stem cells on the radioiodine-induced salivary gland damage in rats
}

\author{
Güleser Saylam¹, Ömer Bayır¹, Salih Sinan Gültekin², Ferda Alparslan Pınarlı, Ünsal Han4, \\ Mehmet Hakan Korkmaz ${ }^{5}$, Mehmet Eser Sancaktar ${ }^{6}$, İlkan Tatar ${ }^{7}$, Mustafa Fevzi Sargon ${ }^{7}$, \\ Emel Çadallı Tatar ${ }^{1}$
}

\begin{abstract}
1 University of Health Sciences, Dıșkapı Yıldırım Beyazıt Training and Research Hospital, Department of Otolaryngology, Head and Neck Surgery, Ankara, Turkey

${ }^{2}$ University of Health Sciences, Dıșkapı Yıldırım Beyazıt Training and Research Hospital, Department of Nuclear Medicine, Ankara, Turkey

${ }^{3}$ University of Health Sciences, Dıșkapı Yıldırım Beyazıt Training and Research Hospital, Department of Stem Cell and Genetic Diagnostic Center, Ankara, Turkey

${ }^{4}$ University of Health Sciences, Dıșkapı Yıldırım Beyazıt Training and Research Hospital, Department of Pathology, Ankara, Turkey ${ }^{5}$ Yıldırım Beyazıt University, Faculty of Medicine, Department of Otolaryngology, Head and Neck Surgery, Ankara, Turkey

${ }^{6}$ Ministry of Health, Samsun Training and Reseach Hospital, Department of Otolaryngology, Head and Neck Surgery, Samsun, Turkey

${ }^{7}$ Hacettepe University, Faculty of Medicine, Department of Anatomy, Ankara, Turkey
\end{abstract}

Radiol Oncol 2017; 51(3): 307-316.

Received 21 December 2016

Accepted 7 April 2017

Correspondence to: Salih Sinan Gültekin, M.D., Department of Nuclear Medicine Dıșkapı Yıldırım Beyazıt Training and Research Hospital, Ankara, Turkey. Phone: + 9031259620 00; E-mail: gultekinsinan@gmail.com

Disclosure: No potential conflicts of interest were disclosed.

Background. To analyze protective/regenerative effects of adipose tissue-derived mesenchymal stem cells (ADMSC) on ${ }^{131}$-Radioiodine (RAI)-induced salivary gland damage in rats.

Materials and Methods. Study population consisted of controls ( $n: 6)$ and study groups (n:54): RAI (Group 1), ADMSC (Group 2), amifostine (Group 3), RAl+amifostine (Group 4), concomitant RAI+ADMSC (Group 5) and RAI+ADMSC after $48 \mathrm{~h}$ (Group 6). We used light microscopy (LM), transmission electron microscopy (TEM), and salivary gland scintigraphy (SGS), and analyzed data statistically.

Results. We observed the homing of ADMSC in salivary glands at $1^{\text {st }}$ month on LM. RAI exposure affected necrosis, periductal fibrosis, periductal sclerosis, vascular sclerosis and the total sum score were in a statistically significant manner $(P<0.05)$. Intragroup comparisons with $L M$ at $1^{\text {st }}$ and $6^{\text {th }}$ months revealed statistically significant improvements in Group $6(P<0.05)$ but not in Groups 4 and 5. Intergroup comparisons of the total score showed that Groups 4 and 5 in $1^{\text {st }}$ month and Group 6 in $6^{\text {th }}$ month had the lowest values. TEM showed vacuolization, edema, and fibrosis at $1^{\text {st }}$ month, and an improvement in damage in $6^{\text {th }}$ month in Groups 5 and 6 . SGSs revealed significant differences for the maximum secretion ratio (Smax) $(P=0.01)$ and the gland-to-background ratio at a maximum count $(G / B G m a x)(P=$ 0.01 ) at $1^{\text {st }}$ month, for $G / B G \max (P=0.01)$, Smax $(P=0.01)$ and the time to reach the maximum count ratio over the time to reach the minimum count (Tmax/Tmin) $(P=0.03)$ at $6^{\text {th }}$ month. $1^{\text {th }}$ and $6^{\text {th }}$ month scans showed differences for Smax and G/BGmax ( $P=0.04)$, but not for Tmax/Tmin ( $p>0.05)$. We observed a significant deterioration in gland function in group 1, whereas, mild to moderate deteriorations were seen in protective treatment groups.

Conclusions. Our results indicated that ADMSC might play a promising role as a protective/regenerative agent against RAl-induced salivary gland dysfunction.

Key words: salivary gland; radioiodine treatment; radiation damage; radiation protection; stem cell transplantation; adipose tissue-derived mesenchymal stem cells 


\section{Introduction}

${ }^{131}$ I-Radioiodine (RAI) is used as an effective and common therapy option in hyperthyroidism and thyroid carcinoma; however, it is frequently associated with salivary gland dysfunction. ${ }^{1}$ Several types of deterministic side effects may occur immediately after administration (short term, first $96 \mathrm{~h}$ ), in the next few months (intermediate, until 3 months), or later (long term: >3 months). ${ }^{2}$ RAIinduced sialadenitis remains a major clinical problem with a rising incidence of thyroid carcinoma due to early detection of small tumors. ${ }^{3}$ Jeong et al. ${ }^{4}$ investigated long-term effects of RAI ablation, and reported that $20 \%$ of patients had salivary gland dysfunction on scintigraphy.

Salivary glands consist of several cell types, but the glands are mainly differentiated according to serous and mucinous components. Parotid glands are most susceptible to RAI damage because of the dominancy of serous glandular tissue. Xerostomia is rare but an important problem that is mainly due to submandibular gland damage after medical irradiation. Xerostomia, or reduced secretion of saliva, compromises a patient's quality of life by corrupting oral and dental health, leading to oral infections, dental caries, taste alterations, nocturnal discomfort, and even difficulties of speaking and swallowing. ${ }^{1-4}$ Therefore, prevention or repair of the salivary gland damage is important.

Salivary gland damage is irreversible after development of radiation necrosis, and available treatments can only increase secretion from the remaining surviving tissue. ${ }^{2}$ Amifostine is one of the most studied agents used to overcome radiationrelated hyposalivation, and its active metabolite (WR-1065) decreases levels of free oxygen radicals. Even though it seems to be a cytoprotective agent, amifostine has many adverse effects, limiting its widespread use. Pilocarpine is used for symptom relief, but none of the medications mentioned above have been advocated for prevention or symptomatic treatment of salivary gland damage. ${ }^{5-10}$ However, to improve the patients' quality of life and decrease the associated morbidities; new regenerative solutions are needed to obtain functional restoration and repair in affected tissues.

Mesenchymal stem cells (MSCs) isolated from the umbilical cord, adipose tissue, lung tissue, and bone marrow have been used as treatment agents for several diseases due to their capacity of tissue regeneration, trophic support, and modulation of the innate immune response. ${ }^{11,12}$ Homing and en- graftment of stem cells have been observed in damaged organs, such as the myocardium and kidney; those stem cells may increase function by reducing the levels of proinflammatory cytokines. ${ }^{13,14}$

External radiation-induced salivary gland damage has been investigated in some studies. Lombaert et al. showed bone marrow MSCs could travel to damaged salivary glands following mobilization, subsequently inducing the repair processes, which improved gland function and morphology. ${ }^{15}$ Jeong et al. investigated the effects of transplantation of human submandibular gland stem cells (hSGSCs) to radiation-damaged rat salivary glands. ${ }^{16}$ Their data suggested that mesenchymallike stem cells could be used for treatment of RAIinduced salivary gland damage.

In this controlled animal study, we investigated the protective/regenerative effects of adipose tissue-derived MSCs (ADMSC) on the RAI-exposed rat salivary glands using structural and functional examinations.

\section{Materials and methods}

\section{Study population and design}

Sixty female Wistar albino rats weighed 230 - 250 $\mathrm{g}$ were used in this study. The animals were kept under standard conditions (temperature: $24-26^{\circ} \mathrm{C}$; relative humidity: $65-70 \%$ ) in 12-h light/12-h dark cycles, with access to water and seeds ad libitum. RAI was administered at a dose of $74 \mathrm{MBq}(2 \mathrm{mCi})$ by oral route to induce salivary gland damage. ADMSC (i.p; $2 \times 10^{6}$ ) and amifostine (i.v; $200 \mathrm{mg} / \mathrm{m}^{2}$ ) were used as cytoprotective/regenerative agents against the effects of radiation. Our main goal was to determine whether ADMSC had a regenerative effect besides its cytoprotective effect.

The study protocol was approved by Dişkapı Yıldırım Beyazıt Education and Research Hospital's Animal Ethics Board (2013/38), and instructions of local/international animal research were followed. The national/international regulations of radiation safety and waste disposal for contaminated secretion and materials of radio-exposed rats were also followed.

The study groups were designed as follows:

1. Control group: $n=6$,

2. RAI alone group (Group $1, \mathrm{n}=9$ ),

3. ADMSC alone group (Group 2, $\mathrm{n}=9$ ),

3. Amifostine alone group (Group 3, n=9),

4. Simultaneous RAI plus amifostine group (Group 4, n =9): RAI and amifostine were given at the same time. 
5. Simultaneous RAI plus ADMSC group (Group 5, n =9): RAI and ADMSC were given at the same time.

6. RAI and late ADMSC administration group (Group 6, n =9). This group was named as "late administration group" since ADMSC was administered $48 \mathrm{~h}$ after RAI.

Salivary gland scintigraphy was performed at baseline, and after 1 and 6 months. Three animals in each group were sacrificed at the end of $1^{\text {st }}$ month, and the rest were sacrificed at the end of $6^{\text {th }}$ month of the study. The specimens were examined under the light microscope (LM) and transmission electron microscope (TEM). The study and the control groups were compared in terms of RAI-induced tissue damage. Intergroup comparisons were also done among the study groups.

\section{Preparation of adipose-derived mesenchymal stem cells}

Fried and Moustaid-Moussused's protocol was used to culture adipose tissue. ${ }^{17}$ Adipose tissue explants at a volume of $0.5 \mathrm{~cm}^{3}$ were extracted from the inguinal fat pad of the rats. The tissues were transported from the operating room to the laboratory in a transport buffer (phosphate buffered solution [PBS], $5.5 \mathrm{mM}$ glucose, and $50 \mathrm{~g} / \mathrm{mL}$ gentamicin), at room temperature. The following procedures were carried out under a laminar flow hood, using sterile equipment. The tissues were transferred to a Petri dish containing $3 \mathrm{~mL}$ of PBS, and minced into $10-15 \mathrm{mg}$ pieces. The pieces were extensively washed with $10 \mathrm{~mL}$ of PBS over a filter containing sterile cotton bandage fabric. Thereafter, they were gently shaken for a short period following transferred to a $25 \mathrm{~cm}^{2}$ culture flask, containing $1 \mathrm{~mL}$ of PBS. Adipose tissue pieces were cultured within MSC medium (Dulbecco's Modified Eagle's Medium - low glucose; Invitrogen; Thermo Fisher Scientific, Waltham, MA, USA), 20\% fetal bovine serum (Biological Industries Israel Beit-Haemek Ltd., Kibbutz Beit-Haemek, Israel), $100 \mathrm{U} / \mathrm{mL}$ of penicillin, $100 \mathrm{mg} / \mathrm{mL}$ of streptomycin (Biological Industries Israel Beit-Haemek Ltd., Kibbutz BeitHaemek, Israel), and $20 \mathrm{~mL} / \mathrm{L}$ of L-glutamine. They were incubated at $37^{\circ} \mathrm{C}$ and in $5 \% \mathrm{CO}_{2}$. Culture medium was changed every three days, and colonyforming unit-fibroblasts were observed at $14-16$ days with a $70 \%$ confluency of the culture plate. The detached cells were subcultured on a standard culture dish, using $0.25 \%$ trypsin in $0.02 \%$ ethylenediaminetetraacetic acid. After three passages, the cell suspensions were defined with MSC markers including CD11b/c (-), CD45(-), CD90(+), CD44(+), and CD49(+) with the FACS Aria III cell sorter, and stored at $-80^{\circ} \mathrm{C}$ DMEM-LG medium included $10 \%$ DMSO and $10 \%$ FBS.

To label ADMSC in vitro, $10 \mu \mathrm{L}$ of BrdU solution ( $1 \mathrm{mM}$ BrdU in $1 \times$ Dulbecco's PBS, BD Pharmingen, San Diego, CA, USA) was added for each milliliter of tissue culture medium, and incubated for 2 hours. Cell culture density was $2 \times 10^{6}$ cells $/ \mathrm{mL}$.

To demonstrate the labeled ADMSC, BrdU staining was performed on $6 \mathrm{~mm}$ thick slides those were prepared from formalin-fixed, paraffin-embedded tissues, after deparaffinization in xylene to detect BrdU ion. The slides were transferred into 100\% and $95 \%$ alcohol, then endogenous peroxidase activity was blocked with $3 \%$ hydrogen peroxide, and the slides were subsequently rinsed with PBS. Finally, the sections were immunohistochemically stained with a BrdU detection kit (BD Pharmingen) to show the presence of BrdU+ cells.

\section{Light microscopy}

The excised salivary gland samples were harvested and fixed in 10\% formaldehyde solution. After the paraffinization procedure, tissue sections were stained with hematoxylin and eosin, and a blinded pathologist examined all specimens under the light microscope (Olympus BX-50; Olympus Corporation, Tokyo, Japan). Salivary gland damage was categorized into three stages (0: no damage; 1: mild damage; 2: moderate damage; and 3: severe damage) for each of the following findings: acinar epithelial cells (edema, vacuolization, periacinar inflammation, and necrosis), interstitial space (periductal sclerosis, fibrosis, and mucus leakage), ductal system (ductal ectasia), and vascular system (sclerosis). A total score of histological findings reflected the sum of RAI-induced damage in tissues.

\section{Transmission electron microscopy}

Tissue samples were put into $2.5 \%$ gluteraldehyde for 24 hours for primary fixation, and they were post-fixed in $1 \%$ osmium tetroxide after washing with Sorenson's phosphate buffer solution $(\mathrm{pH}$ : 7.4). In the next step, washing with the same buffer and dehydration in increasing concentrations of alcohol series were done. After dehydration, the tissues were washed with propylene oxide, and embedded in epoxy resin embedding media. Semithin $(2 \mu \mathrm{m})$ and ultra-thin $(60 \mathrm{~nm})$ sections of the 
TABLE 1. Histological findings in the salivary glands of the rats. Mean values of salivary gland damage parameters are given. *Details of groups are given below the table

\begin{tabular}{|c|c|c|c|c|c|c|c|c|c|c|c|c|c|c|c|c|c|c|c|c|c|c|}
\hline $\begin{array}{l}\text { Site of } \\
\text { damage }\end{array}$ & $\begin{array}{l}\text { Investigated } \\
\text { parameters }\end{array}$ & \multicolumn{3}{|c|}{ Control } & \multicolumn{3}{|c|}{ Group 1} & \multicolumn{3}{|c|}{ Group 2} & \multicolumn{3}{|c|}{ Group 3} & \multicolumn{3}{|c|}{ Group 4} & \multicolumn{3}{|c|}{ Group 5} & \multicolumn{3}{|c|}{ Group 6} \\
\hline \multirow{2}{*}{$\begin{array}{l}\text { Acinar } \\
\text { epithelial } \\
\text { cell } \\
\text { damage }\end{array}$} & Vacuolization & 4.33 & 3.5 & ns & 6.67 & 6.33 & ns & 5 & 7 & 0.04 & 4.67 & 4.17 & ns & 4 & 5.33 & ns & 5 & 3.67 & ns & 5.33 & 2 & 0.02 \\
\hline & Necrosis & 0.67 & 2.33 & ns & 0 & 1.33 & 0.04 & 2 & 0.5 & ns & 1.67 & 1 & ns & 0 & 1 & ns & 0.33 & 0 & ns & 0.67 & 0.17 & ns \\
\hline $\begin{array}{l}\text { Ductal } \\
\text { system } \\
\text { damage }\end{array}$ & Ectasia & 3 & 3.33 & ns & 6.33 & 5.83 & ns & 4.33 & 6 & ns & 3.67 & 2.5 & ns & 2.67 & 4.67 & 0.01 & 3.67 & 3.5 & ns & 3.33 & 0.83 & 0.04 \\
\hline \multirow[t]{2}{*}{$\begin{array}{l}\text { Interstitial } \\
\text { space } \\
\text { damage }\end{array}$} & $\begin{array}{l}\text { Periduktal } \\
\text { sclerosis }\end{array}$ & 0 & 0.17 & ns & 0 & 2.17 & 0.02 & 1.33 & 1.83 & ns & 1 & 0 & 0.03 & 0 & 0.33 & ns & 0 & 0.67 & ns & 0 & 0 & ns \\
\hline & $\begin{array}{l}\text { Periductal mucus } \\
\text { leakage }\end{array}$ & 1 & 0.5 & ns & 1 & 1 & ns & 0.67 & 1.33 & ns & 1.33 & 1 & ns & 0.33 & 0.83 & ns & 0.33 & 0.33 & ns & 3 & 0.5 & 0.02 \\
\hline $\begin{array}{l}\text { Vascular } \\
\text { system } \\
\text { damage }\end{array}$ & Sclerosis & 0 & 0.17 & ns & 1 & 4.5 & 0.01 & 1.67 & 3.5 & ns & 1.33 & 0.5 & ns & 0.67 & 1.17 & ns & 0 & 1.17 & 0.01 & 1.67 & 0.5 & ns \\
\hline & Total & 12.67 & 15.5 & ns & 22.67 & 31.83 & 0.02 & 24.33 & 31.33 & ns & 20.34 & 15.17 & 0.05 & 12 & 22.83 & 0.02 & 13.66 & 15.67 & ns & 21.67 & 7.67 & 0.02 \\
\hline
\end{tabular}

Control = healthy subjects; Group 1= radioiodine; Group 2 = adipose tissue-derived mesenchymal stem cells; Group 3 = amifostine; Group 4 = radioiodine plus amifostine; Group $5=$ radioiodine plus adipose tissue-derived mesenchymal stem cells concomitant; Group $6=$ radioiodine plus adipose tissue-derived mesenchymal stem cells after 48 h; ns = not significant.

obtained from the tissue blocks were cut with an ultramicrotome (LKB Nova, Sweden). Semi-thin sections were stained with methylene blue, and ultra-thin sections were stained with uranyl acetate and lead citrate. Those sections were examined under a light microscope (Nikon Corporation, Tokyo, Japan), and a transmission electron microscope (Jeol JEM 1200 EX (JEOL Ltd., Tokyo, Japan), respectively. The same microscopes were used to photograph the specimens.

\section{Salivary gland scintigraphy}

A double-headed large-field gamma camera (ECAM, Siemens, IL, USA), equipped with a lowenergy, high-resolution collimator was used. After $0.2-0.3 \mathrm{ml}$ bolus intravenous injection of ${ }^{99 \mathrm{~m} T \mathrm{~T}-}$ pertechnetate $(74 \mathrm{MBq})$ through the tail veins of the rats under anesthesia, dynamic images were collected (120 frames at a rate of 1 frame/20 second) for 40 min with a magnification of 1.23 in a
$128 \times 128$-pixel matrix. For image analysis, ovalshaped regions of interest (ROIs) drawn on the right and left salivary gland regions were used. A ROI on the left supraclavicular area was used for background activity. All ROIs had the same size. The image data were processed, and a time-activity curve (TAC) was generated for each subject using a summarization method including background subtraction and three-point smoothing. Functional assessments of TACs were made for following quantitative parameters: The gland-tobackground ratio at a maximum count (G/BGmax) defined the degree of gland parenchymal damage when compared with the background activity since this ratio dropped off due to the parenchymal injury and destruction in a direct manner. The time to reach the maximum count ratio over the time to reach the minimum count (Tmax/Tmin) showed whether the gland activity slowed down due to mostly ductal system damage. It is dependent on the processes of transit in tissue and trans- 
port out of the gland. The maximum secretion ratio (Smax; maximum count - minimum count/ maximum count $\times 100$ ) highlighted secretion capacity of the gland as a percentage.

\section{Statistical analysis}

We used SPSS software (version 18.0 for Windows, SPSS Inc., Chicago, USA) for statistical analysis. Kruskal-Wallis test was employed to compare the groups, Mann-Whitney U test was used to analyze the intergroup differences, and Friedman's test was used to assess the differences in continuous variables.

\section{Results}

\section{Light microscopy findings}

Table 1 and Figure 1 show the histological findings of the salivary glands in the study groups. Normal salivary gland histology was shown in upper horizontal line from control samples (Figure $1 \mathrm{~A}-\mathrm{C}$ ). Homing of ADMSC to RAI-damaged salivary glands and their trans-differentiation into salivary gland cells are seen in Figure 1D-F.

Intragroup comparison of the parameters in the control group showed that none of parameters had statistically significant difference between $1^{\text {st }}$ and $6^{\text {th }}$ months $(P>0.05)$.

In Group 1, destructive effects of RAI on acinar cells, interstitial space and vascular system over time were demonstrated with presence of necrosis $(P=0.04)$, periductal fibrosis $(P=0.02)$, periductal sclerosis $(P=0.02)$, vascular sclerosis $(P=0.01)$, and total sum score $(P=0.02)$. However, the effect of RAI on the ductal system was not significant $(P>$ $0.05)$. RAI-induced necrosis and increased vacuolization (Figure 1G), periductal fibrosis and inflammation (Figure 1H-I) were shown in Figure 1.

In Group 2, we observed statistically significant differences on acinar epithelial cells with an increase in edema $(P=0.05)$, vacuolization $(P=0.04)$ and periductal sclerosis $(P=0.03)$.

In Group 3, the findings were not related to RAI, and we assumed those findings as insignificant.

In, Amifostine plus RAI (Group 4), Amifostine did not exhibit a sufficient protective effect in intragroup comparison; and yet the damage increased in a statistically significant manner in terms of edema $(P=0.02)$, ductal ectasia $(P=0.01)$, periductal fibrosis $(P=0.02)$ and total sum score $(P=0.02)$.

Similarly, in the concomitant administration of stem cells plus RAI (Group 5), we determined a

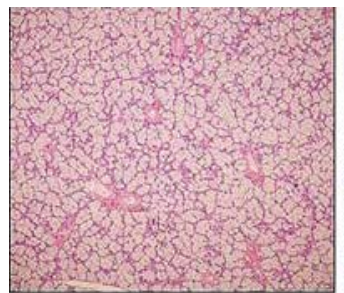

(A)

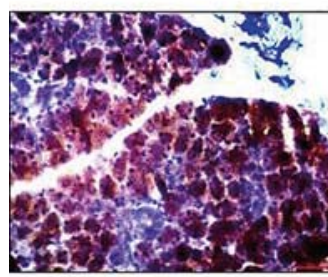

(D)

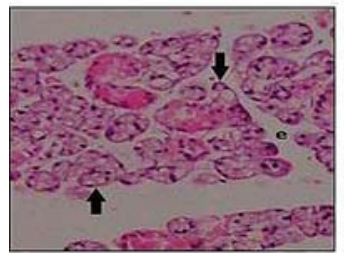

(G)

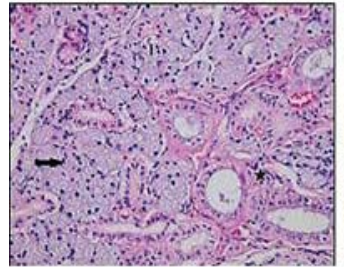
(J) K

FIGURE 1. Histological photographs of salivary gland tissue samples. Pictures on the upper horizontal line show control groups at $1^{\text {st }}$ month evaluation ( $\mathbf{A}$; haematoxylin and eosin (H\&E)X40), and at $6^{\text {th }}$ month evaluation in different magnifications ( $B$; H\&EX200, C; H\&EX400). Pictures on the second horizontal line (D to F; x200 Leica DM 1000) shows the localization of BrdU(+) Adipose Derived Mesenchimal Stem Cells (ADMSC) in the salivary gland (brown stained cells) at $1^{\text {st }}$ month after its intraperitoneal injection in different magnifications. Radioiodine-induced damage in Group 1 is seen in pictures on the third horizontal line (G to I; H\&Ex400, H\&Ex400 and $\mathrm{H} \& \mathrm{Ex} 100$ ). Massive vacuolization, necrosis (black arrow) and edema were shown in G minimal vacuolization (black arrow) and periductal fibrosis (black star) in $\mathbf{H}$ and lenfosit infiltration (black arrow) in I. Pictures on the lower horizontal line (J to L H\&Ex400, H\&Ex200 and H\&Ex40) indicates the improvements in the histological findings (including vacuolization, fibrosis and edema: black arrow; nearly normal mucous acini, black star; nearly normal ductal system) at $6^{\text {th }}$ month evaluation after the late ADMSC administration in Group 6.

statistically significant increase in periductal fibrosis $(P=0.01)$ and sclerosis $(P=0.01)$.

ADMSC seemed the most effective in Group 6. There was a statistically significant decrease on $6^{\text {th }}$ month for edema, vacuolisation, periaciner inflammation, periductal mucus leakage $(P=0.02)$ and ectasia $(P=0.04)$ compared to the findings obtained 

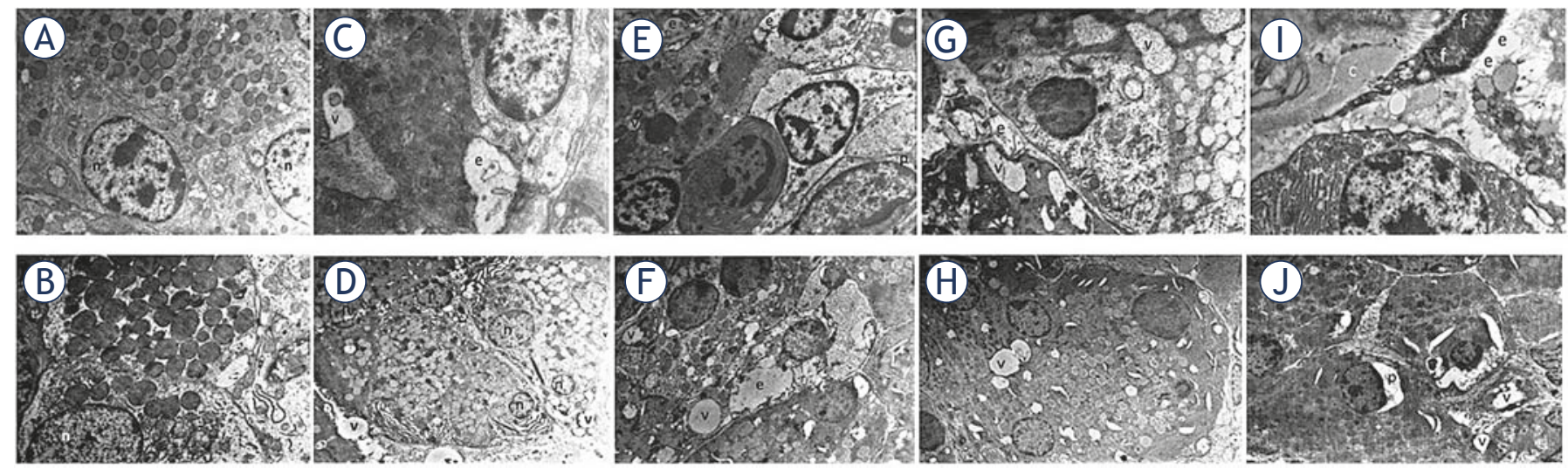

FIGURE 2. The figure (magnification $\times 5000$ ) demonstrates the findings of electron microscopy at months 1 and 6 . (A and B). Normal salivary gland samples of the control group. A and D. Intracellular vacuoles and intercellular edema related to radioiodine in Group 1. E and F. We observed intracellular vacuoles, intercellular edema, nucleus of fibroblast and collagen fibers (fibrosis) at $1^{\text {st }}$ month evaluation in the treatment groups (Groups 5 and 6); G to J. Improvement in cellular damage at $6^{\text {th }}$ month in the stem cell-administered groups (Groups 5 and 6). On the images; c: collagen fibers; e: intercellular edema; f: nucleus of fibroblast; n: nucleus, p: dilated perinuclear cistern; v: intracellular vacuoles.

on month 1. In addition, the sum of all histologic parameters decreased only in Group 6, with late stem cell administration. This improvement in histologic findings were demonstrated in Figure 1J-L.

At $1^{\text {st }}$ month, we found a statistically significantly difference among the groups for periductal fibrosis, sclerosis and the total sum score were $(P$ $<0.05$ ). The differences among the groups were statistically significant for the changes in edema, vacuolisation, necrosis, ectasia, sclerosis, periductal fibrosis, periductal sclerosis, and the total sum score $(P<0.05)$ at $6^{\text {th }}$ month. We supposed that interstitial space damage and total sum score were good indicators of RAI-induced damage. Total sum scores indicated that histologic improvements were statistically significant in all preservative treatment groups (Groups 4, 5, and 6 vs. Group 1). Total sum score was the smallest in Groups 4 and 5 at $1^{\text {st }}$ month, and in Group 6 at $6^{\text {th }}$ month. We concluded that, although concomitant administrations could be effective in the early phase of RAI-induced damage, late stem cell administration (Group 6) was better for recovery of the functional damage over time when compared to the other administration methods.

\section{Electron microscopy findings}

TEM demonstrated cellular damage and fibrosis (Figure 2C-D). Intercellular edema and intracellular vacuolization showed cellular damage.

TEM examinations were normal in the control group at $1^{\text {st }}$ and $6^{\text {th }}$ months. We observed large intracellular vacuoles and intense intercellular ede- ma in Group 1. RAI-induced damage was more distinct in samples obtained at $6^{\text {th }}$ month, since the samples exhibited smaller intracellular vacuoles and minimal intercellular edema (Figure 2). The findings of ADMSC-administered group (Group 2) were identical to the findings of the control group. Minimal vacuolization and fibrosis were seen in Group 3, which was administered amifostine alone, but this was reversible, since the $6^{\text {th }}$ month evaluation was normal. We observed vacuolization, edema, and fibrosis due to RAI damage at $1^{\text {st }}$ month in the treatment groups (Groups 4, 5, and 6). The cellular damage and fibrosis improved in both the stem cell plus RAI-administered groups (Groups 5 and 6) at $6^{\text {th }}$ month (Figure 2). However, the RAI damage was not partially reversible with amifostine administration in-group 4. The TEM findings demonstrated the regenerative/restorative effect of ADMSC on RAI-induced salivary gland dysfunction.

\section{Scintigraphy findings}

The baseline findings were similar for all parameters in all study groups $(P>0.05)$. RAI groups (Groups 1, 4, 5 and 6) and others (Groups 2 and 3) showed statistically significant differences for Smax $(P=0.01)$ and $\mathrm{G} / \mathrm{BGmax}(P=0.01)$, but not for Tmax/Tmin $(P>0.05)$ at $1^{\text {st }}$ month. On the other hand, $6^{\text {th }}$ month scans revealed statistically significantly differences between RAI and non-RAI groups for Smax $(P=0.01)$, G/BGmax $(P=0.01)$ and Tmax/Tmin $(P=0.03)$. Combined treatment groups showed significant differences for $1^{\text {st }}$ and 
TABLE 2. The mean values (the counts from left and right salivary glands) of the Smax, Tmax/Tmin and G/BGmax, and their statistical significance. Baseline and follow-up salivary gland scintigraphies were performed on the subjects who had single treatment (Group 1; radioiodine, Group 2; adipose tissue-derived mesenchymal stem cells, Group 3; amifostine) and combined treatments (Group 4; radioiodine plus amifostine, Group 5; radioiodine plus adipose tissue-derived mesenchymal stem cells concomitant, Group 6; radioiodine plus adipose tissue-derived mesenchymal stem cells after $48 \mathrm{~h}$ )

\begin{tabular}{|c|c|c|c|c|c|c|c|c|c|c|c|c|}
\hline \multirow{2}{*}{ Groups } & \multicolumn{3}{|c|}{ Smax (\%) } & \multicolumn{4}{|c|}{$\operatorname{Tmax} / \operatorname{Tmin}$} & \multicolumn{5}{|c|}{ G/BGmax } \\
\hline & Baseline & $1^{\text {st }} \mathrm{m}$ & $6^{\text {th }} \mathrm{m}$ & $p$ & Baseline & $1^{\text {st }} \mathrm{m}$ & $6^{\text {th }} \mathrm{m}$ & $p$ & Baseline & $1^{\text {st }} \mathrm{m}$ & $6^{\text {th }} \mathrm{m}$ & $p$ \\
\hline Group 2 & 34.74 & 34.31 & 34.62 & ns & 0.06 & 0.06 & 0.07 & ns & 1.59 & 1.57 & 1.58 & ns \\
\hline Group 4 & 33.07 & 30.30 & 28.88 & 0.04 & 0.08 & 0.08 & 0.09 & ns & 1.57 & 1.49 & 1.44 & 0.04 \\
\hline Group 5 & 33.51 & 32.91 & 28.89 & 0.04 & 0.08 & 0.08 & 0.09 & ns & 1.58 & 1.52 & 1.49 & 0.04 \\
\hline Group 6 & 35.55 & 31.60 & 26.07 & 0.04 & 0.07 & 0.07 & 0.09 & ns & 1.60 & 1.51 & 1.36 & 0.04 \\
\hline$p$ & ns & 0.01 & 0.01 & & ns & ns & 0.03 & & ns & 0.01 & 0.01 & \\
\hline
\end{tabular}

G/BGmax = Gland-to-background ratio at a maximum count; $n s=$ Not significant; Smax = Maximum secretion ratio; Tmax/Tmin = Ratio of the time to reach the maximum counts to the time to reach the minimum counts.

$6^{\text {th }}$ month findings for Smax and G/BGmax values $(P=0.04)$, but not for $\operatorname{Tmax} / \operatorname{Tmin}(\mathrm{p}>0.05)$. This might be due to preservation of ductal secretion. RAI-dependent impairment in function at $6^{\text {th }}$ month was the most prominent in Group 1. The measurements for Smax and G/BGmax seemed to be better in concomitant protective administrations with RAI (Groups 4 and 5), but the difference was not statistically significant. Tmax/Tmin ratio was similar among treatment groups with RAI (Groups $4-6$ ). These findings suggested that protective agents could partially overcome functional damage related to RAI (Table 2).

The functional status on a salivary gland scintigraphy can be evaluated easily by a TAC generated from dynamic scintigraphic data. We compared pre- and post-treatment TACs generated from the sequential salivary gland scintigraphies of rats at baseline and at $6^{\text {th }}$ month to observe time-related healing or worsening in the study groups, and to determine protective/regenerative effects of amifostine and ADMSC. Figure 3 depicts the functional change in activity of rat salivary glands over time in RAI and combined treatment groups. A review of the time-sequential findings in Group 1 showed a significant deterioration in function over time with decreased gland uptake and secretion capability (Figure 3A-B). As expected, TACs of two consecutive scans were not different from the baseline in the groups not treated with RAI (Groups
2 and 3). In the analysis of TAC patterns for RAI plus concomitant amifostine and ADMSC groups (Groups 4 and 5) as well as the late ADMSCadministered group (Group 6) mild to moderate deteriorations were seen in function over time in terms of slope of TAC and secretion capability of the gland (Figure 3C-H).

\section{Discussion}

Well-differentiated thyroid cancer treated with RAI ablation results in high survival rates; however, xerostomia associated with RAI, which is seen in approximately $40-50 \%$ of cases, has a severe impact on the quality of life of patients. ${ }^{18,19}$ Various methods have been used to avoid radiation-induced damage to the salivary glands. ${ }^{5-9}$ Amifostine is the only agent approved by United States Food and Drug Administration for salivary gland protection, and its evidence-based protective effects on salivary glands have been shown. However, treatment-associated side effects of this cytoprotective agent including excessive chills, sweating, excessive tearing, dizziness, flushing, voice changes, tremor, nervousness, and diarrhea have limited its use. ${ }^{5-10}$ To our knowledge, this is the first study that showed the favorable effects of ADMSC on RAIinduced salivary gland damage. We administered amifostine in Groups 2 and 3 to compare its effects 


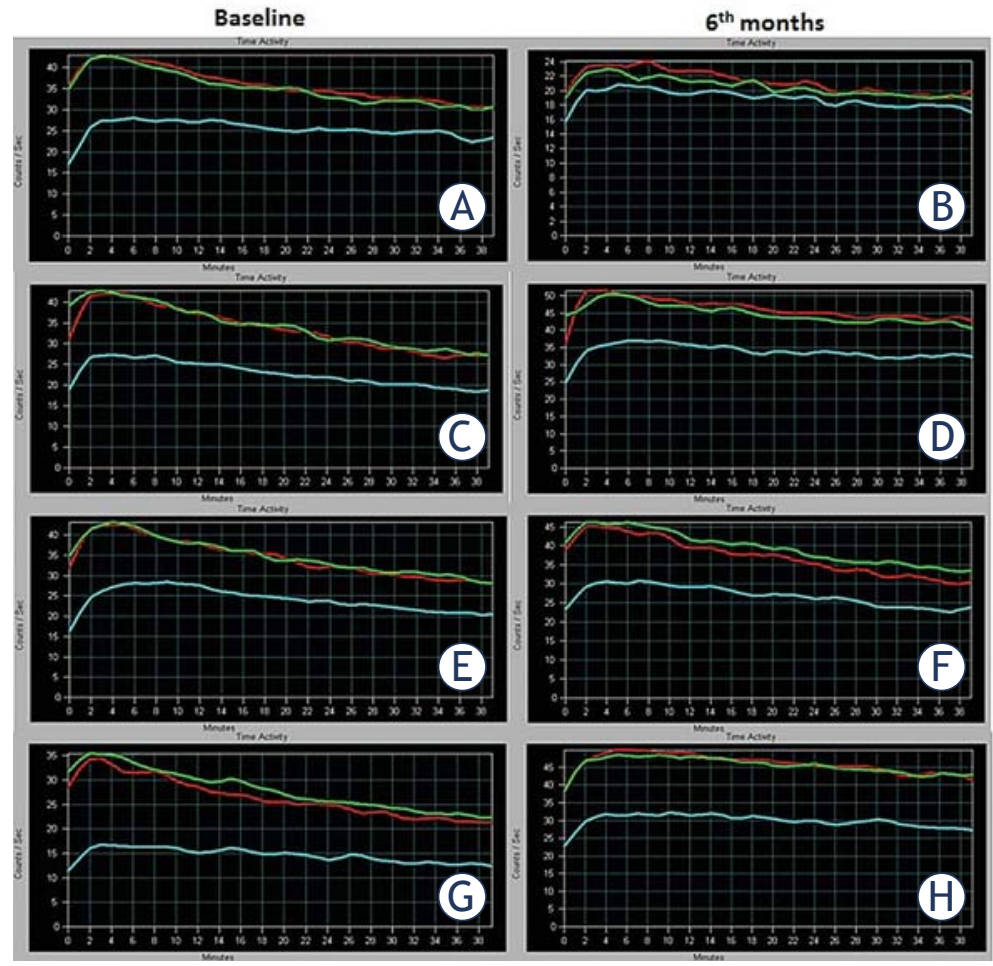

with the protective effect of the stem cells. We also administered cytoprotective agents alone to rule out their unexpected effects. We compared amifostine and stem cells for their protective effects. We found stem cell administration superior to amifostine, and our findings may provide an alternative option, in absence of frequent side effects.

Stem cells can transform into different cells due to their regenerative capacity. ${ }^{20}$ They have recently drawn attraction in regenerative medicine. ${ }^{21}$ MSCs are present in mature tissues as multipotent cells, and can differentiate into specific cells that originate from the mesoderm. Mesenchymal cells have self-renewable properties; they can be easily cultured in vitro, and accepted by target tissues. MSCs can be isolated from different tissues such as bone marrow stromal cells, adipose tissue-derived stem cells, and adult skin stromal cells. Some studies on ADMSCs yielded promising results showing that they could be mutilineage precursor cells, particularly in regenerative therapies. These cells can be easily obtained from donor tissues with minimal morbidity. ${ }^{22,23}$ Although ADMSCs share similar differentiation capabilities with other MSCs, they have higher isolation yield and proliferation ratios in culture when compared to bone marrow stromal stem cells. ${ }^{24}$ ADMSC are not the only precursor of adipocytes; they may also be the progenitor of my-
FIGURE 3. The figure represents functional data obtained from the time-activity curves of rats. A time-activity curve generated from dynamic scintigraphic data depicts the functional changing in activity of rat salivary glands over time. A baseline study (left side; A, C, E, G) and a six-month follow-up study (right side; B, D, F, H) on the rats was performed by ${ }^{99 \mathrm{mTC}} \mathrm{T}-$ pertecnetate salivary gland scintigraphy $(2 \mathrm{mCi}, 120$ frames, 20 second per frame, $40 \mathrm{~min}$ ). The functional differences between baseline and post-treatment status can be easily seen, and compared by time-activity curves. Definitions on a timeactivity curve in this figure are as follows: $x$ axis; examination time (minutes), y axis; count data (counts/second), purple line; left salivary gland activity curve, blue line; right salivary gland activity curve and red line; background tissue activity curve. (A and B). A significant deterioration in function over time with decreased gland uptake and secretion capability with only radioiodine administration (Group 1) is seen. (C to $\mathrm{H}$ ). Radioiodine plus concomitant amifostine (Group 4; C and D), radioiodine plus concomitant (Groups 5; $\mathrm{E}$ and $\mathrm{F}$ ) and after $48 \mathrm{~h}$ (Group 6; G and H) adipose tissue-derived mesenchymal stem cells administrations show mild to moderate deteriorations in function over time in terms of slope of the curve and secretion capability of the gland.

ocytes, osteoblasts, neuronal cells, chondrocytes, and epithelial cells. ${ }^{25,26}$

The first effect of stem cell infiltration is the induction of cytokines. Other healing-related benefits of ADMSC administration are anti-inflammatory activity, an ability to accelerate neovascularization, and the capacity to promote restoration of epithelial integrity. ${ }^{24}$ Our results indicated that ADMSC administration resulted in a structural/functional recovery, as this preventive effect was associated with its ability to foster cytokine release and antiinflammatory effects. Stem cells migrate to salivary glands and promote restoration and neovascularization, which results in functional restoration. Histological improvement following ADMSC administration, particularly in the late period may be associated with neovascularization and regeneration capacity of the cells. Our microscopic and scintigraphic findings demonstrated that ADMSCs were homing to salivary glands, and they could protect from permanent tissue damage and irreversible function loss.

Lombaert et al. ${ }^{15}$ were first to show the potential use of stem cell transplantation for functional rescue of the salivary glands. They concluded that granulocyte-colony stimulating factor with mobilized bone marrow-derived stem cells might be effective for regenerating and functionally 
restoring externally irradiated salivary glands. Jeong et al. ${ }^{16}$ isolated and amplified tissue-specific hSGSCs. They developed a culture system (lasting $4-5$ weeks) without any selection. The researchers found that transplantation of hSGSCs to radiationdamaged rat salivary glands rescued the function of the submandibular gland, and improved morphological damage. In another study, the authors systematically administered human ADMSC to mice immediately after local irradiation, and this was repeated once a week for three times. ${ }^{27}$ They used salivary flow rates for functional assessment, and immunofluorescence histochemistry for morphological evaluation. The authors suggested that intravenous human ADMSC administration was a candidate therapy for the treatment of radiationinduced salivary gland damage. In light of all those studies, one may say that adult stem cell transplantation may be useful for functional and morphological regeneration of radiation damage in human salivary glands.

Our study differs from the others methodologically, and in terms of its findings in various aspects. ${ }^{8,10,15,16}$ Internal instead of external radiation exposure was used to induce salivary gland damage. Salivary gland scintigraphy with ${ }^{99 \mathrm{~m} T c-}$ pertechnetate was employed for functional evaluation instead of saliva collection or salivary flow rate. In addition, we used TEM to show the healing of damage on ultrastructural level. According to LM findings, initial damage occurs in the interstitial space and vascular system, which results in fibrosis and functional impairment. Sequential scintigraphy findings showed that the parenchyma damage was more than ductal damage. We may conclude that RAI-induced tissue damage is progressive. We observed a decrease in RAI-induced salivary gland damage by administration of amifostine and ADMSC. Concomitant stem cell infiltration had a protective effect; however, the late stem cell administration was restorative. This finding represents evidence of the protective and regenerative effects of ADMSC. Ultrastructural improvements were seen in the stem cell-administered groups in the vascular system damage demonstrated by TEM as vacuole formation and fibrosis. Our scintigraphic findings demonstrated the functional damage of RAI administration, which was prevented with amifostine and stem cell administration.

In this study, we found that the stem cell administration might be more effective than amifostine in rats, concomitant stem cell infiltration could reduce damage, and the late stem cell infiltration could restore tissue more than the other treatments. Our
TEM findings indicated that vacuolization, edema, and fibrosis were present at the $1^{\text {st }}$ month evaluation of the preventive treatment groups. One promising result of this study was the improvements seen at $6^{\text {th }}$ month. The ultrastructural healing was better in the stem cell plus RAI-administered groups compared to the amifostine plus RAI groups.

In fact, the patients are administered RAI in hypothyroid state, after thyroidectomy. They have a high concentration of RAI in the body due to especially its slow clearance..$^{28}$ In our study, we did not perform thyroidectomy. We administered a higher dose of RAI as given dose per gram of tissue compared to that used in a standard clinical setting. Thus, we may say that we could safely test the effect of protective agents against damage caused by RAI in nonthyroidectomized rats.

Our findings demonstrated that late stem cell administration was more effective than other treatments tested, and all stem cell administrations provided a mild to moderate protection against RAI damage in salivary gland scintigraphy. Therefore, we may suggest a combination of both applications for prevention/restoration of RAI-induced salivary gland damage, with minimal side effects. Further studies are needed to enlighten the effect of stem cell therapy in humans.

We did not investigate releasing factors after stem cell administration; we accepted this as a limitation of our study. We know that stem cells could migrate to all tissues. ${ }^{11,12}$ However, we focused on only salivary gland damage.

In conclusion, radiation-induced hyposalivation remains as a major problem following external radiation or RAI. Since permanent dysfunction decreases the patients' quality of life, prevention of salivary gland damage and/or restoration of gland functions are important. In the current study, we showed the preventive and restorative capacity of stem cells, with histologic and functional improvements. The underlying key point of histologic and functional restoration could be the ultrastructural improvement of cellular damage. Stem cell infiltration may be a novel and promising method to prevent of xerostomia after radiation. We believe that this valuable approach has a potential to be a standard treatment option in near future after further studies are conducted in humans.

\section{Acknowledgements}

This study was financially supported by a grant from Dışkapı Yıldırım Beyazıt Training and 
Research Hospital Scientific Research Support Committee.

\section{References}

1. Jensen SB, Pedersen AM, Vissink A, Andersen E, Brown CG, Davies AN, et al. Salivary Gland Hypofunction/Xerostomia Section, Oral Care Study Group, Multinational Association of Supportive Care in Cancer (MASCC)/ International Society of Oral Oncology (ISOO). A systematic review of salivary gland hypofunction and xerostomia induced by cancer therapies: prevalence, severity and impact on quality of life. Support Care Cancer 2010; 18: 1039-60. doi:10.1007/s00520-010-0827-8

2. Mandel SJ, Mandel L. Radioactive iodine and the salivary glands. Thyroid 2003; 13: 265-71. doi:10.1089/105072503321582060

3. Fard-Esfahani A, Emami-Ardekani A, Fallahi B, Fard-Esfahani $P$, Beiki $D$ Hassanzadeh-Rad A, et al. Adverse effects of radioactive iodine-131 treatment for differentiated thyroid carcinoma. Nucl Med Commun 2014; 35: 808-17. doi:10.1097/MNM.0000000000000132

4. Jeong SY, Kim HW, Lee SW, AhnBC, Lee J. Salivary gland function 5 years after radioactive iodine ablation in patients with differentiated thyroid cancer: direct comparison of pre- and postablation scintigraphies and their relation to xerostomia symptoms. Thyroid 2013; 23: 609-16. doi:10.1089/ thy.2012.0106

5. Bohuslavizki KH, Klutmann S, Jenicke L, Kröger S, Buchert R, Mester $\mathrm{J}$, et al. Salivary gland protection by S-2-(3-aminopropylamino) ethylphosphorothioic acid (amifostine) in high-dose radioiodine treatment: results obtained in a rabbit animal model and in a double-blind multi-arm trial. Cancer Biother Radiopharm 1999; 14: 337-47. doi:10.1089/ cbr.1999.14.337

6. Joseph ப, Bhartiya US, Raut YS, Hawaldar RW, Nayak Y, Pawar YP, et al. Radioprotective effect of Ocimum sanctum and amifostine on the salivary gland of rats after therapeutic radioiodine exposure. Cancer Biother Radiopharm 2011; 26: 737-43. doi:10.1089/cbr.2011.1014

7. Sagowski C, Wenzel S, Metternich FU, Kehrl W. Studies on the radioprotective potency of amifostine on salivary glands of rats during fractionated irradiation: acute and late effects. Eur Arch Otorhinolaryngol 2003; 260: 42-7. doi:10.1007/s00405-002-0496-4

8. Pimentel MJ, Filho MM, Araújo M, Gomes DQ, DA Costa U. Evaluation of radioprotective effect of pilocarpine ingestion on salivary glands. Anticancer Res 2014; 34: 1993-9.

9. Koca G, Gültekin SS, Han U, Kuru S, Demirel K, Korkmaz M. The efficacy of montelukast as a protective agent against 131/-induced salivary gland damage in rats: scintigraphic and histopathological findings. Nucl Med Commun 2013; 34: 507-17. doi:10.1097/MNM.0b013e32835ffecd

10. Hamlar DD, Schuller DE, Gahbauer RA, Buerki RA, Staubus AE, Hall J, et al. Determination of the efficacy of topical oral pilocarpine for postirradiation xerostomia in patients with head and neck carcinoma. Laryngoscope 1996; 106: 972-6.

11. Ding DC, Chang YH, Shyu WC, Lin SZ. Human umbilical cord mesenchymal stem cells: a new era for stem cell therapy. Cell Transplant 2015; 24: 339-47. doi:10.3727/096368915X686841

12. Ramdasi S, Sarang S, Viswanathan C. Potential of mesenchymal stem cell based application in cancer. Int J HematolOncol Stem Cell Res 2015; 9: 95-103.

13. Luo CJ, Zhang FJ, Zhang L, Geng YQ, Li QG, Hong Q, et al. Mesenchymal stem cells ameliorate sepsis-associated acute kidney injury in mice. Shock 2014; 41: 123-129. doi:10.1097/SHK.0000000000000080

14. Weil BR, Manukyan MC, Herrmann JL, Wang Y, Abarbanell AM, Poynter JA, et al. Mesenchymal stem cells attenuate myocardial functional depression and reduce systemic and myocardial inflammation during endotoxemia. Surgery 2010; 148: 444-52. doi:10.1016/j.surg.2010.03.010

15. Lombaert IM, Wierenga PK, Kok T, Kampinga HH, deHaan G, Coppes RP Mobilization of bone marrow stem cells by granulocyte colony-stimulating factor ameliorates radiation-induced damage to salivary glands. Clin Cancer Res 2006; 12: 1804-12. doi:10.1158/1078-0432.CCR-05-2381
16. Jeong J, Baek H, Kim YJ, Choi Y, Lee H, Lee E, et al. Human salivary gland stem cells ameliorate hyposalivation of radiation-damaged rat salivary glands. Exp Mol Med 2013; 45: e58. doi:10.1038/emm.2013.12

17. Fried SK, Moustaid-Moussa N. Culture of adipose tissue and isolated adipocytes. Methods Mol Biol 2001; 155: 197-212. doi:10.1385/1-59259231-7:197

18. Alexander C, Bader JB, Schaefer A, Finke C, Kirsch CM. Intermediate and long-term side effects of high-dose radioiodine therapy for thyroid carcinoma. J Nucl Med 1998; 39: 1551-4.

19. Solans R, Bosch JA, Galofré P, Porta F, Roselló J, Selva-O'Callagan A, et al. Salivary and lacrimal gland dysfunction (sicca syndrome) after radioiodine therapy. J Nucl Med 2001; 42: 738-43.

20. Wei X, Yang X, Han ZP, Qu FF, Shao L, Shi YF. Mesenchymal stem cells: a new trend for cell therapy. Acta Pharmacol Sin 2013; 34: 747-54. doi:10.1038/ aps.2013.50

21. Horwitz EM, Le Blanc K, Dominici M, Mueller I, Slaper-Cortenbach I, Marin FC, et al. International Society for Cellular Therapy. Clarification of the nomenclature for MSC: The International Society for Cellular Therapy position statement. Cytotherapy 2005; 7: 393-5. doi:10.1080/14653240500319234

22. Mayshar Y, Ben-David U, Lavon N, Biancotti JC, Yakir B, Clark AT, et al. Identification and classification of chromosomal aberrations in human induced pluripotent stem cells. Cell Stem Cell 2010; 7: 521-31. doi:10.1016/j. stem.2010.07.017

23. Zuk PA, Zhu M, Ashjian P, De Ugarte DA, Huang Jl, Mizuno H, et al. Human adipose tissue is a source of multipotent stem cells. Mol Biol Cell 2002; 13: 4279-95. doi:10.1091/mbc.E02-02-0105

24. Salibian AA, Widgerow AD, Abrouk M, Evans GR. Stem cells in plastic surgery: a review of current clinical and translational applications. Arch Plast Surg 2013; 40: 666-75. doi:10.5999/aps.2013.40.6.666

25. Zuk PA, Zhu M, Mizuno H, Huang J, Futrell JW, Katz AJ, et al. Multilineage cells from human adipose tissue: implications for cell-based therapies. Tissue Eng 2001; 7: 211-28. doi:10.1089/107632701300062859

26. Brayfield C, Marra K, Rubin JP. Adipose stem cells for soft tissue regeneration Handchir Mikrochir Plast Chir 2010; 42: 124-8. doi:10.1055/s-0030-1248269

27. Lim JY, Ra JC, Shin IS, Jang YH, An HY, Choi JS, et al. Systemic transplantation of human adipose tissue-derived mesenchymal stem cells for the regeneration of irradiation-induced salivary gland damage. PLoS One 2013; 8: e71167. doi:10.1371/journal.pone.0071167

28. Gültekin SS, Sahmaran T. The efficacy of patient-dependent practices on exposure rate in patients undergoing iodine-131 ablation. Health Phys 2013; 104: 454-8, doi:10.1097/HP.0b013e318283f853 